\title{
LETRAMENTO(S)/ALFABETIZAÇÃO EM CONTEXTOS MULTILÍNGUES DE ANGOLÁ E GUINÉ-BISSAU
}

\author{
Aracy Alves Martins \\ Universidade Federal de Minas Gerais (UFMG), Belo Horizonte - MG, Brasil \\ Silvestre Filipe Gomes"* \\ Universidade Onze de Novembro (UON), Cabinda-Angola \\ Virgínia José Baptista Cá*** \\ Liceu João XXIII, Bissau-Guiné-Bissau
}

RESUMO: A Pesquisa em Rede sobre relações raciais, diversidade sociocultural e interculturalidade em países de língua portuguesa analisa, pelo viés da Análise Crítica do Discurso, segundo Van Dijk, obras literárias, segundo Paulino e Cosson, manuais escolares, segundo Dionísio e Costa Val, e documentos oficiais relacionados a políticas linguísticas e culturais, segundo Calvet. Dessa forma, enfatiza diálogos sul/sul, segundo Santos e Meneses, e Munanga e Gomes, e cooperação horizontal entre países de língua portuguesa, partindo de orientações das Leis brasileiras 10.639/2003 e 11.645/2008, que instituem o estudo da História e Cultura dos africanos e indígenas nas escolas brasileiras. Este texto apresenta duas investigações de mestrado que focalizam tensões entre língua oficial e língua(s) materna(s), nos processos de Letramento(s), em Angola e GuinéBissau, desenvolvidas por pesquisadores desses dois países, na Faculdade de Educação da Universidade Federal de Minas Gerais, no Brasil, que apontam para possibilidades do ensino bilíngue.

Palavras-chave: Letramento(s). Políticas linguísticas. Língua oficial. Línguas maternas.

\section{LITERACY (IES) IN ANGOLA AND GUINEA-BISSAU MULTILINGUAL CONTEXTS}

ABSTRACT: The Network Research about racial relationships, sociocultural diversity and interculturality in Portuguese-speaking countries aims at

http://dx.doi.org/ 10.1590/0102-4698164867

* Doutora em Educação pela Universidade Federal de Minas Gerais (UFMG). Professora Associada da Faculdade de Educação. Pesquisadora do Grupo de Pesquisa do Letramento Literário/GPELL, no interior do Centro de Alfabetização, Leitura e Escrita (CEALE). E-mail: < aracymartins60@gmail.com > .

“" Mestre em Educação pela Universidade Federal de Minas Gerais (UFMG). Docente e pesquisador do Instituto Superior de Ciências de Educação da Universidade Onze de Novembro, Cabinda-ANGOLA.

E-mail: < silvestrefilipeg@gmail.com >

"." Mestre em Educação pela Universidade Federal de Minas Gerais (UFMG). Coordenadora Pedagógica no Liceu João XXIII, Bissau-GUINÉ-BISSAU.E-mail: < vina1485@yahoo.com.br > . 
analyzing, through the perspective of Critical Discourse Analysis, according Van Dijk, the literary works, according Paulino and Cosson, the school manuals according Dionisio, Costa Val and Marcuschi, and the official documents related to cultural and linguistic policies, according Calvet. Therefore, it emphasizes South/South dialogues, according Santos and others authors, and horizontal cooperation among Portuguese-speaking countries, based on the guidance of Brazilian laws 10.639/2003 and 11.645/2008, that establish the study of African and Indigenous peoples' history and culture at Brazilian schools. This text presents two Master course researches that focus on tensions between official language and mother tongues in literacy (ies) processes in Angola and Guinea-Bissau, developed by researchers from both countries at Faculty of Education of Federal University of Minas Gerais/ Brazil, that indicate the possibilities of the bilingual education.

KEYWORDS: Literacy (ies). Linguistic policies. Official language. Mother tongues.

$\begin{array}{ll}\text { Na kal lingu ke n na skirbi } & \text { Em que língua escrever } \\ \text { Na diklarasons di amor? } & \text { As declarações de amor? } \\ \text { Na kal lingu ke n na kanta } & \text { Em que língua cantar } \\ \text { Storias ke n kontado? } & \text { As histórias que ouvi contar? } \\ {[\ldots . .]} & {[\ldots]} \\ \text { Pa n kontal na kriol? } & \text { Falarei em crioulo? } \\ \text { Na kriol ke n na kontal! } & \text { Falarei em crioulo! }\end{array}$

(SEMEDO, 1996, p. 11)

\section{INTRODUCุÃO}

Considerando o conceito de Letramento(s) no Brasil, buscamos em Soares (1998), que construiu o verbete Letramento por encomenda da Unesco, uma conceituação: "Letramento é o estado ou condição de quem não só sabe ler e escrever, mas exerce as práticas sociais de leitura e de escrita que circulam na sociedade em que vive, conjugando-as com as práticas sociais de interação oral" (SOARES, 1999, p. 3, grifo nosso).

Além disso, pensando em novos convívios, em novas práticas cotidianas, Dionísio (2006, p. 43, grifo nosso) refere-se a Literacia(s)/ Letramento(s), em Portugal, como:

[...] uma prática sociocultural que podemos reconhecer como própria deste “domínio de prática”: a escola. É o reconhecimento da acção de tais processos e dispositivos que cria a possibilidade de, ao falarmos, hoje, de literacia, o fazermos já no plural: literacias ou mesmo multiliteracias, literacias múltiplas, etc.; marca-se, por essa forma, a existência da especificidade das práticas que 
envolvem o escrito em múltiplos domínios da vida como, por exemplo, a família, os lugares de trabalho, a associação, etc. Desde logo porque, em cada um desses domínios, são visíveis modos "preferidos" de fazer sentidos com os textos, modos particulares de os usar e, mesmo, de sobre eles falar.

A pesquisa em Rede - Língua e Literatura: relações raciais, diversidade sociocultural e interculturalidade em países de língua portuguesa -, no intuito de dar suporte para a formação de professores da Educação Básica no Brasil, teve início em 2008, por pesquisadores ligados ao Centro de Alfabetização, Leitura e Escrita/Ceale e ao Núcleo de Estudos e Pesquisas sobre Relações Raciais e Ações Afirmativas/ Nera), da Faculdade de Educação da Universidade Federal de Minas Gerais/FaE/UFMG, envolvidos em atividades pluridisciplinares, no Curso de Especialização para professores da Rede Municipal de Belo Horizonte, da área de "História da África e Culturas Afro-Brasileiras: uma introdução à Lei 10.639/03"', que estabelece a obrigatoriedade, no Brasil, do estudo da História e das Culturas Afro-Brasileiras, em todos os níveis de ensino (MUNANGA; GOMES, 2006; SILVA et al., 2008).

Considerando os Manuais escolares como apoio pedagógico para professores, a pesquisa buscou, inicialmente, analisar manuais do Brasil e de países africanos de língua portuguesa (Angola, Cabo Verde, Guiné-Bissau, Moçambique, São Tomé e Príncipe), buscando compreender os manuais por concepções do(s) Letramento(s), da Cultura, do Currículo, da Formação de Leitores, das Comunidades de Leitores (SOARES, 1998; DIONÍSIO, 2006; ROJO, 2009; FORQUIN, 1993; CASTRO; RODRIGUES; SILVA; SOUSA, 1999; DIONÍSIO, 2000; COSTA VAL; MARCUSCHI, 2005; BUNZEN, 2005). Essas análises apontaram para investigar outras facetas, que estabeleceram outros eixos de pesquisa, conforme se lê a seguir.

O segundo eixo, A produção literária para crianças e jovens, surgiu como proposta de investigação complementar das antologias dos manuais escolares, em contexto de formação de professores e de Letramento Literário, quanto à formação de leitores (professores e alunos) sensíveis e críticos (PAULINO; COSSON, 2009).

Além disso, outras questões foram emergindo, pelo ponto de vista de interações horizontais, Sul/Sul, das Epistemologias do Sul (SANTOS et al., 2010), em contextos plurilíngues, em que se estuda na escola somente a língua oficial, instituindo-se o terceiro eixo: Tensão Língua Oficial/Línguas maternas.

A pesquisa trabalha, teórico-metodologicamente, pelo ponto de vista da Análise Crítica do Discurso - ACD -, procurando perceber a linguagem não somente como uma prática discursiva, mas também, 
e sobretudo, como uma prática social, ou seja, como um modo de ação pelo qual as pessoas podem agir sobre o mundo, sobre as outras pessoas (FAIRCLOUGH, 2001; VAN DIJK, 2008).

O presente texto trata, especificamente, das tensões entre línguas, em Guiné-Bissau e Angola ${ }^{2}$, dentro do terceiro eixo da Pesquisa em Rede: relações entre língua oficial/língua(s) materna(s), em virtude de uma aproximação mais recente e mais concreta com o campo, através de investigações produzidas por dois pesquisadores, integrantes da Pesquisa em Rede, interessados em discutir questões relativas a Contextos Multilíngues em seus países, no Programa de Pós-graduação em Educação: Conhecimento e Inclusão Social, da Faculdade de Educação da UFMG, em Belo Horizonte, Brasil (GOMES, 2014; CÁ, 2015). Nesses dois países, a língua oficial portuguesa coexiste de maneiras diferenciadas com as línguas locais. Por isso, neste texto, é dada a palavra aos dois investigadores, para que os leitores tomem conhecimento do que foi possível problematizar, nesses dois contextos multilíngues, através das suas Dissertações de Mestrado: Lingua e ensino em contexto de diversidade linguistica e cultural: o caso de Guiné-Bissau (CÁ, 2015); Relações entre língua oficial e línguas locais na escola: como as crianças de aldeias de Cabindal Angola aprendem o português e em português (GOMES, 2014).

Ambas as pesquisas, por uma perspectiva qualitativa, coletaram dados em escolas dos respectivos países: a primeira, partindo da questão "Diante do plurilinguismo constitutivo das práticas orais em Guiné-Bissau, em que sentidos os processos de aquisição da leitura e da escrita de forma monolíngue dificultam ou auxiliam a aquisição de habilidades linguísticas?", apresenta como objetivo investigar as práticas de alfabetização e letramento presentes nos discursos dos professores alfabetizadores, tendo em vista a diversidade linguística e cultural guineense. Metodologicamente, foi realizado um estudo com duas escolas de Bissau, uma pública e uma escola em Regime de Autogestão, com professoras de primeira classe, composto por observação de sala de aula, análise de materiais e entrevistas semiestruturadas com seis professores das séries iniciais, entre eles: um diretor e uma pedagoga das escolas do Ensino Básico. A segunda, tendo como preocupação a questão "Como as crianças, que, a partir do seio familiar, falam uma língua local angolana de origem africana, aprendem o português?”, produziu seus dados de pesquisa em contato com três escolas do Ensino Primário, localizadas em meios rurais, na periferia de CabindaAngola, utilizando-se, metodologicamente, de observação em sala de aula, entrevistas às professoras, aos diretores e a alguns encarregados de 
educação das escolas primárias das três aldeias e no acompanhamento de aulas e dos momentos recreativos dos alunos.

Para esse debate, outros pesquisadores estabelecem relações entre as línguas locais, a cultura, a oralidade, a cognição e a desenvoltura dos alunos, ensejando políticas linguísticas (SEMEDO, 2010; SCANTAMBURLO, 2013; DIALLO, 2007; LOPES FILHO, 2015; CARREIRA, 1984; CARDOSO, 2005; VEIGA, 2004; CALVET, 2007, entre outros).

Assim, ao longo deste texto, os leitores conhecerão, através de informações, perguntas e reflexões dos dois pesquisadores (GOMES, 2014; CÁ, 2015), as relações entre as línguas locais e a língua oficial língua do país, da escola, dos documentos -, nos processos de ensino/ aprendizagem dos alunos em fase de alfabetização e letramento(s), na escola básica, em práticas sociais de diferentes contextos multilíngues: em Guiné-Bissau, várias línguas étnicas guineenses e uma língua nacional; em Angola, línguas locais de origem africana. Após essas duas seções, que buscam apresentar um contexto histórico e, também, perspectivas futuras das Políticas Linguísticas de cada país, há uma seção que tem o objetivo de instaurar uma reflexão entre pesquisadores/educadores sobre a importância da apropriação de aspectos dos processos de Letramento(s) em cada país de língua portuguesa, limite desta pesquisa, com suas especificidades culturais e linguísticas, e não por imposição de concepções generalizantes.

\section{GUINÉ-BISSAU: LÍNGUAS ÉTNICAS GUINEENSES/LÍNGUA NACIONAL?}

Esta pesquisa teve, primeiramente, acesso a poemas de GuinéBissau, a partir das contribuições da poeta guineense Odete Semedo (2010), pesquisadora, mencionada na epígrafe, retomada aqui, por sua temática vigorosa e por sua produção literária, propositadamente em duas línguas, crioulo e português, com uma interrogação que inquieta e uma exclamação que grita, com energia, Entre o ser e o amar:

\author{
Ma kal sinal ke n na disa \\ Netus di no djorson? \\ N na girtal na kriol \\ Pa rekadu pasa di boka pa boka \\ Tok i tchiga si distinu
}

\author{
Mas que sinais deixar \\ Aos netos deste século? \\ Em crioulo gritarei \\ A minha mensagem que de boca em boca \\ Fará a sua viagem
}

(SEMEDO, 1996, p. 11, grifo nosso) 
Segundo Augel (2006, p. 86), "falar na sua língua materna e original, gritar mesmo, é o impulso primeiro do eu poético", que espera contar com a oratura dos guineenses, como prática social, de boca em boca. O termo oratura é utilizado, aqui, como Semedo (2010, p. 80), "para designar todos os textos da tradição oral, recolhidos e fixados pela escrita: contos, cantigas, provérbios, entre outros", conforme se lê mais abaixo.

Amâncio (2008, p. 51) afirma que "a literatura de textos literários da Guiné-Bissau permitiu a percepção da força linguística do crioulo guineense e da tradição oral”. Augel (2006, p. 75) complementa, referindo-se a diferentes manifestações do crioulo na oratura, ou seja, nos contos (storia), nas adivinhas (dibiña), nos provérbios (ditu):

Djunbai é um termo crioulo que pode ser traduzido como "convívio" [...], de interação social em que se enquadram o narrador ou a narradora de estórias e seu público. Através dessas estórias, afloram de modo plástico e convincente as experiências e vivências das diferentes comunidades culturais que constituem a textura da sociedade guineense. (AUGEL, 2006, p. 80)

Isso se confirma nas palavras de Semedo (2010, p. 87, grifo nosso), em sua tese de doutorado, quando diz:

Hoje, é em crioulo que também se leem poemas de autores modernos, contos da oratura guineense e em crioulo se podem escutar, ainda, canções que denunciam problems sociais e políticos que afetam a população. O crioulo guineense vem se afirmando, a cada dia, como língua da expressão literária guineense, pois mesmo quando não se escreve nessa língua, os textos dos autores se mostram repletos de expressões em crioulo, de frases que, embora escritas na língua portuguesa, revelam a estrutura do crioulo.

Posteriormente, a maior parte dos dados foi coletada, in loco, em escolas de Bissau, pela pesquisadora da Pesquisa em Rede, Virgínia Cá (CÁ, 2015, p. 22), cuja dissertação questionava inicialmente: “Qual a visão dos professores sobre o fato de a alfabetização em contexto escolar acontecer na segunda língua (a língua portuguesa), e não na língua mais falada (a Língua crioula)?”.

Historicamente, nos seus estudos etnográficos, trabalhando entre Guiné e Cabo Verde, Carreira, etnógrafo e historiador, referese ao nascimento dessa língua híbrida "[...] o crioulo, essa importante língua de comunicação verbal falada nas ilhas de Cabo Verde, na Guiné e nas Caraíbas" (Carta de António Carreira a Victor de Sá Machado, em 28/10/1982, Cf. Lopes Filho, 2015, p. 93), que "teria 'nascido' na 'Guiné' e depois levado para as ilhas de Cabo Verde” (CARREIRA, 1984, p. 15). 
Para bem definir o que pode ser chamado de "crioulo", esse autor considerou como pontos essenciais "determinar cientificamente em que limites o português serviu de suporte lexical ao crioulo cabo-verdiano [...] e possuir um conhecimento bastante das línguas africanas que lhe deram as estruturas gramaticais (CARREIRA, 1984, p. 10, grifo nosso).

Nesse sentido, Augel esclarece a opção de Scantamburlo sobre o termo Guineense em lugar do termo crioulo:

Luigi Scantamburlo, sacerdote italiano, com longos anos de experiência no país, defende a adoção do termo "guineense" para a língua majoritária da GuinéBissau, pois "esse termo não tem as conotações pejorativas veiculadas pela palavra 'crioulo', relativamente ao termo língua, testemunhando, ao mesmo tempo, o prestígio obtido face à sociedade da Guiné-Bissau nestes últimos trinta anos" (SCANTAMBURLO apud AUGEL, 2006, p. 70).

Segundo Diallo (2007), estima-se em cerca de 20 o número de línguas faladas na Guiné-Bissau, das quais as mais importantes, do ponto de vista numérico, são: Kriol [crioulo], balanta, fula, português, mandinga, manjaku e papel.

Os linguistas definem os crioulos como um sistema linguístico em que o léxico é tomado na sua maioria de empréstimos da língua base, a língua do dominador, e as estruturas são resultantes dos substratos das línguas africanas. Foi do contato do português com as línguas étnicas mais correntes naquele território que nasceu o crioulo guineense que acabou se tornando o idioma da unidade nacional. (AUGEL, 2006, p. 70)

Por outro lado, Scantamburlo (2013, p. 27) apresenta as 12 línguas que se fazem presentes em Guiné-Bissau, partindo das mais faladas: Fula, Balanta, Mandinga, Manjaco, Papel, Felupe, Beafada, Bijagó, Mancanha, Nalu, Crioulo Guineense e Português. Além das línguas referidas, existem línguas com poucos números de falantes, como listado em ordem alfabética por Scantamburlo (2013, p. 27), "Bagas, Baiotes, Bambarãs, Banhuns, Cassangas, Conhagui, Cobianas (ou Coboianas), Jacancas, Jalofos (ou Wolof), Landumãs, Padjadincas (ou Badjaranca), Saracolés (ou Soninkés), Sereres (ou Nhomincas), Sossos (ou Jaloncas), Tandas, Timenés". O crioulo é falado por $44,31 \%$, e o português, por $11,08 \%$ da população, entre 1979 e 2009 (CÁ, 2015, p. 64-65).

De acordo com os dados da pesquisa de Cá, as línguas faladas pelos alunos da escola pública pesquisada, das quais 30 dos alunos declararam falar a língua crioula em casa, nenhum aluno declarou falar o português e 13 alunos falam línguas maternas, entre elas: Balanta, 
Biafada, Bijagó, Crioulo, Felupe, Fula, Mancanha, Manjaco, Mansonga, Mandinga, Nalu, Pepel e Sosso. Observa-se, ainda, que, dos 30 alunos, 18 declararam falar suas línguas étnicas (CÁ, 2015, p. 137).

Como se pode perceber, segundo Scantamburlo (2013), GuinéBissau é um país cuja língua oficial é o português, mas várias línguas nacionais compõem o quadro linguístico do país, entre elas o crioulo, que vem a ser língua do convívio e da interação social. Apesar do prestígio que a língua guineense (crioulo da Guiné) vem conquistando como a língua da interação social e da unidade nacional de maior comunicação entre as pessoas, a língua portuguesa medeia a inserção das crianças guineenses no mundo da cultura escrita escolar, pois " $O$ ensino oficial continua a manter a língua portuguesa como única língua de ensino-aprendizagem" (SCANTAMBURLO, 2002, p. 1).

Por isso, o questionamento da pesquisadora guineense continua, ao longo do seu trabalho de pesquisa:

Diante do plurilinguismo constitutivo das práticas orais em Guiné-Bissau, em que sentidos os processos de aquisição da leitura e da escrita de forma monolíngue dificultam ou auxiliam a aquisição de habilidades linguísticas? A exclusão de língua crioula no processo de ensino-aprendizagem, bem como a imposição de língua oficial, há muito vêm sendo apontadas como um dos principais problemas que podem contribuir para o insucesso escolar dos nossos alunos. Diante dessa realidade, trabalhamos com a hipótese de que: o ensino em diálogo com a língua crioula pode facilitar a alfabetização, visto ter grande relevância social e cultural. (CÁ, 2015, p. 22)

Segundo a mesma pesquisadora, a imposição de uma única língua oficial, ecoando práticas coloniais na contemporaneidade póscolonial, leva-nos a problematizar o ensino do português no processo de alfabetização e as práticas de letramento escolar, desvinculado da língua materna do aprendiz. Nossa pesquisa busca compreender as práticas de letramento envolvidas nos processos de alfabetização de alunos que têm o crioulo como primeira língua (L1) e o português como segunda língua (L2), e como dialogam - ou não - com as práticas plurilíngues em Guiné-Bissau.

As crianças guineenses entram em contato com o mundo da cultura escrita escolar, sendo privadas dos conhecimentos linguísticos prévios já adquiridos, tanto na aquisição de uma das, aproximadamente, 25 línguas pertencentes aos diferentes grupos étnicos que constituem nossa população, como também conhecimentos culturais e práticas de letramento relacionadas ao crioulo, língua nacional (CÁ, 2015, p. 18).

O nosso interesse por essa questão vem da necessidade de compreender as consequências da política de proibição do uso do crioulo nas escolas no processo de alfabetização e letramento 
de crianças. Apesar da proibição e da discriminação sofrida pelos estudantes falantes do crioulo, na maioria dos casos, os alunos aprendem a falar primeiro o crioulo para depois aprenderem o português, que é a língua das escolas, dos documentos - desde os tempos coloniais (CÁ, 2015, p. 18).

A pesquisadora lança mão da sua própria experiência de infância, enquanto aluna, para pensar suas questões de pesquisa:

Quando comecei como professora da educação infantil, em Bissau pude perceber a importância da língua crioula na educação básica e como essa língua é importante no processo de ensino-aprendizagem. As crianças tinham muitas dificuldades quando seus processos de alfabetização se davam em português e, muitas vezes, era necessário que eu explicasse em crioulo para uma boa compreensão por parte dos alunos. Isso, porque, de certa forma, para esses alunos, a língua portuguesa é equivalente a uma "língua estrangeira" (LE), mesmo sendo a língua oficial (LO). A realidade desses alunos não se distancia da minha, pois a minha experiência como aluna, de escutar o professor ou diretor dizer que não se pode falar em crioulo, mas somente em português no recinto escolar, me levou a perceber as minhas limitações enquanto falante do português. Meus pais sempre me orientaram para ser responsável nos estudos. Quando tirei notas negativas ou vermelhas, cheguei em casa triste. (CÁ, 2015, p. 19)

Tal experiência contribuiu para que a pesquisadora levantasse questões relevantes durante a organização da sua pesquisa:

Embora, nesses cinco anos tenha passado direto sem reprovações, isso não bastava, pois algumas inquietações pairavam sobre a minha mente, a respeito da língua de ensino, e isso despertou em mim as indagações que levantamos neste trabalho. Dentre elas, destacaram-se algumas como principais razões desta discussão:

a) a obrigatoriedade do uso da língua portuguesa em todas as instituições públicas e privadas;

b) a diversidade linguística e cultural dos alunos;

c) a língua portuguesa como única língua de ensino-aprendizagem e

d) a inclusão das línguas maternas no sistema educativo. (CÁ, 2015, p. 19)

Segundo depoimentos dos professores entrevistados, os alunos que chegam da zona rural, muitas das vezes, não falam o português nem o crioulo; falam as suas línguas maternas aprendidas no meio familiar, usadas apenas nas suas comunidades e que não têm ligação com a língua portuguesa que se aprende na escola.

Nessas circunstâncias, em suas reflexões, Cá chega a apontar, em um dos seus subtítulos, a língua como um dos principais fatores que pode contribuir para o insucesso escolar:

Devido à complexidade que envolve a temática, o fracasso dos alunos deve ser analisado pelos vários fatores e um desses fatores é o linguístico. Muitos alunos 
abandonam a escola ainda muito novos e apresentam baixos níveis de aprendizagem, porque não têm um domínio satisfatório e nem trazem de casa uma base linguística que lhes permitam um uso equilibrado da língua. A linguagem da escola, a legítima, tem limitado o processo de ensino-aprendizagem desses alunos, sobretudo das camadas populares, principalmente das zonas rurais. (CÁ, 2015, p. 164)

Após apresentar dados coletados nas duas escolas pesquisadas em Bissau, em que os alunos, que falam o crioulo guineense ou línguas étnicas apreendidas no meio familiar, são confrontados a aprender a língua de ensino e, ao mesmo tempo, o código da língua escrita, como se fosse a Língua Materna, a pesquisadora continua com sua pergunta inicial.

É importante buscar saber se indagações como essa já foram levantadas em experiências anteriores.

Em se tratando de Experiências Anteriores, sabe-se da parceria entre Amílcar Cabral e Paulo Freire, em Guiné-Bissau, assim como em outros países africanos ex-colônias de Portugal, pela ênfase na práxis política, na cultura popular e na educação em sua função libertadora, "uma concepção educacional que leve em conta a revolução cultural” (FREIRE, apud GADOTTI, 2012, p. 119).

Amílcar Cabral, dirigente do Partido Africano da Independência da Guiné e Cabo Verde (PAIGC) - a primeira organização de libertação das colônias portuguesas, fundada em 1956 -, insistia na importância de todo revolucionário estudar. Dizia ele: "devemos, portanto, diante das perspectivas favoráveis da nossa luta, estudar cada problema em profundidade e encontrar para ele a melhor solução. Pensar para agir e agir para pensar melhor". Era o político motivando o pedagógico (CABRAL, 1974, p. 15 apud GADOT'TI, 2012, p. 62).

Embora o governo revolucionário tenha decretado que a alfabetização fosse em português, Freire, educador brasileiro, por uma pedagogia emancipadora/libertadora, considerava mais coerente fazê-la em crioulo, buscando explicitar:

Nos círculos de cultura tornou-se evidente que os progressos em português, que era a língua oficial do país e das suas escolas, como língua do programa de alfabetização eram extremamente lentos. Esta lentidão deixava claro que o português era completamente alheio às práticas sociais diárias do vilarejo. Os vilarejos não conheciam o português, mesmo na sua forma oral. Os grupos étnicos falam sua língua nativa africana e muitas pessoas, mas não todas, falam crioulo. Esta língua, uma forma de dialeto derivado do português e enriquecido pelas linguagens tradicionais africanas, tornou-se difundida na Guiné-Bissau durante a luta de libertação nacional, quando, justamente, assumiu o papel de língua oral entre os grupos étnicos. Por isso, hoje é considerada a língua nacional do país. (IDAC, 1979, p. 42, grifo nosso) 
Paulo Freire não usava o termo letramento, introduzido posteriormente nesse campo de estudos. Todavia, nesse trecho, emprega a expressão práticas sociais, utilizada por Magda Soares, mais tarde, para conceituar letramento (Cf. SOARES, 1998).

O Centro de Educação Popular Integrada (CEPI), de 1977 a 1984, inspirou-se nas experiências da luta por independência política que, no campo da educação, foram marcadas fortemente pela visão da educação libertadora. Cabral não era só um revolucionário da luta política pela libertação nacional, mas, assim como Freire escreve: "a Amílcar Cabral, educador-educando de seu povo" (CÁ, 2015, p. 98).

O CEPI colocou o problema da língua de ensino e do ensino da língua nacional, neste caso o português que era, sobretudo, uma língua estrangeira. $\mathrm{Na}$ realidade, um guineense deveria "possuir" três línguas- a língua da tabanca, que é em geral a língua da sua etnia, o crioulo-português, língua franca das zonas de mestiçagem cultural como as cidades e seus subúrbios e o português adotado como língua nacional, mas na realidade pouco falado e compreendido nas cidades. (SENA, 1995, p. 75, grifo nosso)

O resultado alcançado mostrou que esse modelo não deveria limitar-se somente à Educação Popular Integrada, mas que seria necessário levar suas práticas a toda sala de aula. Então, foram substituídos os CEPI pelos Centros Experimentais de Educação e Formação (CEEF), que, por sua vez, entraram com a nova componente: Formação. A falta de outros Projetos, investindo para o desenvolvimento na zona rural, dificultou o avanço do mesmo.

Durante a vigência dos CEEF, os materiais eram produzidos todos em crioulo, a partir de alfabeto de base lexical portuguesa, porém baseado nos fonemas da língua crioula, com o objetivo da difusão do bilinguismo no ensino guineense.

As escolas bilíngues do Projeto dos CEEF do INDE (Instituto Nacional para o Desenvolvimento da Educação), do Ministério da Educação, funcionavam em três centros: um centro em Cufar (Catió); outro, em Uno (Ilhas) e em Bará (Canchungo). Os professores e os pesquisadores que participaram do Projeto CEEF produziram diversos trabalhos sobre a experiência, os quais permitem ter uma avaliação consistente dos avanços e das dificuldades encontradas (CÁ, 2015, p. 100-101).

O Projeto tinha financiamento da Comunidade Econômica Europeia (CEE), que depois foi transformada na União Europeia (UE). Porém o financiamento era canalizado diretamente pela ONG Centro de Informação Documentação Amílcar Cabral (CIDAC), em Portugal, que geria os fundos e dava apoio técnico. Tinha também 
apoio técnico e financeiro do Serviço Holandês de Cooperação e Desenvolvimento (SNV). O governo nacional não apoiava o projeto financeiramente. Nas entrevistas realizadas, um dos professores afirma: "E1 - D5: Surgiu a ideia de alfabetização de crianças em crioulo / até porque existia uma metodologia própria para a transição de crioulo para português / que devia ser trabalhada de $1^{\mathrm{a}}$ a $2^{\mathrm{a}}$ classe /".

Nos dados, nota-se essa mesma constatação, em entrevista feita com técnico-investigador do INDE e pesquisador do Projeto CEEF:

\section{E2- T.I: Chegamos a uma conclusão / se soubermos articular a língua portuguesa e a língua nacional (crioulo) / com uma dosagem certa neste caso / o resultado pode surpreender / Pensamos que no $1^{\circ}$ trimestre de $2^{a}$ classe / deve ser introduzida a oralidade (língua portuguesa) com o aluno / assim quando chegar na $3^{a}$ classe não terá muito problema com a lingua portuguesa. (CA, 2015, p. 101-102)}

O problema da escolha da língua em que ocorreria a alfabetização sempre foi, e é, uma das grandes limitações no sistema educativo guineense. Paulo Freire, nas suas visitas ao país, já apontava a importância de a alfabetização acontecer em língua crioula. Freire percebeu a urgência da utilização da língua guineense no processo de ensino-aprendizagem a partir das suas reflexões sobre os processos educativos. Da mesma forma, as experiências dos CEEF mostraram importantes resultados do ensino bilíngue (crioulo/português). O Projeto CEEF deu importante contribuição para a difusão e a valorização da língua nacional. No entanto, ele teve a duração de oito anos até 1994, quando terminou por falta de financiamento. Assim, havia interesse e boa vontade de alguns profissionais em dar continuidade ao Projeto bilíngue. O professor Doutor Luigi Scantamburlo foi um desses profissionais que tiveram a louvável iniciativa de implementar o Projeto de Apoio ao Ensino Bilíngue no Arquipélago das Ilhas Bijagós (PAEBB) (CÁ, 2015, p. 19-20).

Hoje em dia, é cada vez maior o número de falantes do crioulo e a presença da língua crioula nas escolas é frequente, ainda que ela seja proibida no recinto escolar. A experiência e o conhecimento linguístico da língua crioula por parte das crianças não têm sido explorados no processo de alfabetização (CÁ, 2015, p. 20).

Sobre Políticas Linguísticas, em Guiné-Bissau, Diallo (2007 apud CÁ, 2015, p. 94-95) reafirma que não há uma política linguística definida no país; e vai ainda mais longe ao dizer que, apesar de grande prestígio que lhe é atribuído pela Lei, o português convive sobre bases sociais estreitas. Para Fonseca:

A política linguística em Guiné, através de um decreto-lei 7/2007 de 12 de 
novembro de 2007, obriga a utilização da língua portuguesa em todas as instituições públicas, nomeadamente nas escolas e, especialmente, dentro da sala de aula e no recinto escolar. (FONSECA, 2011, p. 92 apud CÁ, 2015, p. 95)

Assim, é preciso definir o papel e o lugar que cada língua ocupa por meio da política linguística. Scantamburlo esclarece que:

Na Guiné-Bissau o multilinguismo é uma realidade e esta realidade deve ser encarada como uma riqueza e não como uma ameaça à unidade nacional. Além disso, o multilinguismo, se bem gerido, garante aos cidadãos o direito linguístico, que foi reconhecido como um dos direitos fundamentais no Artigo 29 da "Declaração Universal de Direitos Linguísticos". (SCANTAMBURLO, 2002, p. 40)

Assim, nos tempos atuais, as perguntas de Cá continuam, em se tratando de Políticas Linguísticas: por que não alfabetizar as crianças também na língua do convívio, da socialização e da interação social do cotidiano, a partir de uma perspectiva plurilíngue? (CÁ, 2015, p. 20).

\section{ANGOLA: LÍNGUAS LOCAIS DE ORIGEM AFRICANA?}

Com base na investigação do pesquisador angolano Silvestre Gomes, para além do português, existem oito principais línguas angolanas de origem africana, com 90 (noventa) a 100 (cem) variantes, umbundu, kimbundu, kikongo, tchokwé, fiote/ibinda, nganguela, nyaneca-bumbi e kwanyama. Nenhuma dessas línguas tem a categoria de oficialidade (status), ficando apenas no plano de relações mais próximas, em nível local (GOMES, 2014, p. 58).

Sobre Políticas Linguísticas, segundo o pesquisador angolano, há, no seu país, uma experiência-piloto da inserção de línguas locais no Sistema de Ensino, que ainda está na sua fase inicial. Foram aprovados, a título experimental, pela Resolução 3/78, de 23 de Maio de 1987, do Conselho de Ministros, os alfabetos das línguas kikongo, kimbundu, umbundu, cokwe, oxikwanyama e mbunda e suas respectivas regras de transcrição (GOMES, 2014, p. 66).

Com a aprovação dos alfabetos e das normas de transcrição das seis línguas, Angola começava um processo de planificação linguística, abrindo, assim, a possibilidade de políticas linguísticas regionais, já que as línguas cujos alfabetos foram aprovados eram de circunscrições regionais. As línguas com alfabetos aprovados pelo Estado estão em vias de ser inseridas no Sistema de Ensino, mas essa inserção precisa de um instrumento legal que possa conferir às referidas línguas um posicionamento social, ou seja, a definição do estatuto dessas línguas. Ao serem inseridas, serão avaliadas em que categoria? Línguas nacionais, línguas co-oficiais? (GOMES, 2014, p. 60). 
Segundo Faulstich (1998), o conceito de planificação linguística se apoia num projeto linguístico coletivo. Por visar à harmonização linguística, a planificação deverá resultar de um consenso social para que seja bem-sucedida. Uma planificação linguística que se paute por um trabalho inclusivo, reunindo as línguas e/ou auscultando os falantes das diversas línguas ou dialetos de uma mesma língua, contribui para o estabelecimento de uma política linguística nacional. Ainda para a autora, a planificação é regulamentada pelas disposições jurídicas que, em matéria de língua, acabam por se constituir num conjunto de regras legisladoras (FAULSTICH, 1998 apud GOMES, 2014, p. 59).

Nesse sentido, podemos afirmar que a planificação linguística é uma matéria reservada para o Estado, que tem o poder de legislar sobre as questões atinentes à(s) língua(s).

A partir do momento em que o Estado se preocupa em administrar sua situação
linguística, apresenta-se o problema de saber de que meios ele dispõe para isso.
Como intervir na forma das línguas? Como modificar as relações entre as línguas?
Quais processos que permitem passar de uma política, estágio de escolhas gerais,
ao estágio de implementação do planejamento linguístico? (CALVET, 2007, p. 61)

As respostas às questões apresentadas pelo autor constituem pontos fundamentais para a planificação linguística. Um grupo de pessoas isolado não pode decidir sobre a forma a dar a uma língua. É ao poder estatal que está reservada essa prerrogativa. Quando se fala de padronização de uma língua, está aí implícita a existência de uma variedade de maneiras de falar, e a padronização é o ato e o momento de se escolher qual língua ensinar, qual língua usar nas situações legais e que regras devem ser respeitadas para que seja instituído o conceito de certo e errado. Só o Estado, nas vestes dos poderes que detém sobre os cidadãos, poderá enfrentar qualquer reação, e só ele poderá impor as regras.

Entretanto, entre outros importantes fatores, como o uso generalizado em várias instâncias sociais, é também por vontade política que outra situação pode se estabelecer, na relação entre as classes sociais, em determinados países, como em África. De acordo com Calvet (2007), os Estados podem promover ou despromover o status de uma determinada língua, o que quer dizer que o prestígio de uma língua não depende da própria língua, mas, sim, dos interesses que a classe dominante tem em relação a essa língua. Assim, um Estado pode determinar, segundo critérios de natureza política, qual ou quais línguas serão alçadas à condição de língua oficial (CALVET, 2007 apud GOMES, 2014, p. 56).

Para uma planificação linguística, Calvet (2007) apresenta os equipamentos necessários para conduzir uma boa política 
linguística. O primeiro equipamento é a escrita, que deverá obedecer a determinados estágios, começando pela atribuição de um sistema de escrita para línguas ágrafas, o que implica, em primeiro lugar, o estabelecimento de uma descrição fonológica, para, depois, escolher um tipo de escrita: alfabética ou não alfabética, e, se for o caso, o tipo de alfabeto. A segunda fase da escrita será a divulgação do sistema de escrita selecionado, através de abecedários, manuais, da organização de campanhas de alfabetização, da introdução da língua escrita no sistema escolar, no meio gráfico.

Dentro dessa planificação, falta, ainda, um equipamento, que é o repertório lexical. Calvet (2007) apresenta um segundo equipamento da planificação linguística: o léxico. Todas as línguas possuem um repertório lexical, pois é esse corpus vocabular que permite a comunicação entre os falantes de cada língua, mas, para as línguas que, por via de uma planificação linguística, saem da situação de ágrafas, há uma necessidade de se criarem os canais de compreensão de objetos e ideias vindas de outras culturas e da tecnologia. Aqui se notará a necessidade de se pedir emprestado das outras línguas termos que designam conceitos criados pelo avanço técnico-científico. Em algumas línguas, como kimbundu, umbundu e kikongo, o repertório lexical é mais documentado, por já possuírem dicionários.

O esforço do governo para inventariar as línguas tem a ver com a necessidade de se reconhecer Angola não como país monolíngue, mas como um país onde uma variedade grande de línguas locais de origem africana convive com a língua portuguesa, língua que foi adotada como oficial logo após a independência.

A Constituição de 2010, no Artigo 21, introduz a expressão "línguas angolanas de origem africana: que a Lei promete proteger, valorizar e dignificar como património cultural, e promover o seu desenvolvimento, como línguas de identidade nacional e de comunicação" Constituição (GOMES, 2014, p. 72, grifo nosso).

Como sua pesquisa foi realizada em Cabinda, o pesquisador acrescenta que, desde 2001, na "Estratégia Integrada para Melhoria do Sistema da Educação (2001-2015)", o Conselho de Ministros reconhece a língua de Cabinda como diferente do kikongo, ao traçar como uma das tarefas a "edição e produção de 14 títulos (manuais) para alfabetização e pós-alfabetização em língua portuguesa e em línguas nacionais: umbundu, kimbundu, kikongo, tchokwé, ibinda, nganguela, nyaneca-humbi e kwanyama" (CONSELHO DE MINISTROS, 2001, p. 30 apud GOMES, 2014, p. 73).

Desde 2008, o Instituto de Línguas Nacionais (ILN) e o Instituto Nacional de Investigação e Desenvolvimento da Educação 
(INIDE) vêm realizando seminários em todas as províncias, com vistas à preparação de condições para a inserção das línguas locais de origem africana no Sistema de Ensino. No quadro desses seminários metodológicos, ressaltou-se que o estudo das línguas nacionais e da cultura de cada região constitui elemento essencial para o desenvolvimento de um povo, por caracterizar a identidade dos cidadãos duma determinada zona (GOMES, 2014, p. 74).

Em síntese, as questões linguísticas, em Angola, fazem suscitar muitos debates, sobretudo, quando se fala da valorização das línguas angolanas de origem africana. No contexto angolano, a denominação "língua materna" é interpretada como sinônimo de línguas locais de origem africana, mas, na realidade, não são apenas as línguas angolanas de origem africana que podem ser consideradas maternas no contexto linguístico angolano. O português, apesar de ser uma língua de origem externa, é a maior língua materna que se encontra em Angola, pois tem o maior número de falantes, tanto como língua materna, quanto como segunda língua. As línguas locais de origem africana, designadas por muitos como línguas nacionais e maternas, têm um raio de influência muito limitado, não passando do domínio local ou regional, razão por termos adotado, a denominação "línguas locais de origem africana". O processo de inserção dessas línguas no sistema de educação formal obedece a critérios geográficos ou regionais, evitando conflitos etnolinguísticos; portanto cada zona linguística nacional ensina e aprende a sua língua (GOMES, 2015, p. 77).

Questões como as implicações políticas, como a definição de um estatuto das línguas locais de origem africana, a sua oficialização como língua de trabalho e de escolarização permanecem abertas. Às implicações políticas se juntam as questões com implicações pedagógicas, como a preparação de materiais didáticos em línguas de origem africana, a tomada de consciência, por parte dos professores, da importância do uso das línguas locais no processo de compreensão dos conteúdos científicos (GOMES, 2014, p. 148).

Os mecanismos da inserção de línguas locais de origem africana no ensino, entre outros temas, estão ainda por merecer outros estudos. Do ponto de vista político, é tarefa do Estado a planificação linguística e a adoção de políticas normativas sobre a sistematização e a valorização dessas línguas. Do ponto de vista pedagógico, caberá à escola materializar as políticas concebidas superiormente pelos órgãos governamentais no que toca o ensino em línguas locais de origem africana. Em suma, os resultados desta pesquisa, caso sejam aproveitados pelas autoridades educativas e pela comunidade 
acadêmica do país, poderão contribuir para a implementação de políticas linguísticas no sistema de ensino (GOMES, 2014, p. 149).

\section{ALFABETIZAĈ̣̃O E LETRAMENTO(S)}

Para pensar processos de Literacias(s)/Letramento(s) e Alfabetização em Contextos Multilíngues, as pesquisas apresentadas neste texto trazem produtivas contribuições. Guiné-Bissau centra-se em ricas experiências anteriores de valorização do crioulo - guineense -, enquanto que Angola investe em possibilidades de Políticas Linguísticas a serem implementadas pelo Estado, a fim de responder a questões que permeiam essas discussões, apontando ambos os estudos para uma experimentação educativa plurilíngue, mesmo que seja de modo bilíngue, em que "cada zona linguística nacional", além da língua oficial, "ensina e aprende a sua língua" (GOMES, 2014, p. 77).

Em se tratando de todos esses discursos, de todas essas tensões, torna-se fundamental pensar uma formação de professores que possa considerar os processos de Letramento(s) e Alfabetização (SOARES, 1998) como práticas sociais de leitura e escrita, associadas à escolarização dos sujeitos, em seus contextos.

Soares (2004), tratando de suas experiências em processos de formação de professores brasileiros, acrescenta que "desnecessário se torna destacar, por óbvias, as consequências, nesse novo quadro referencial, para a formação de profissionais responsáveis pela aprendizagem inicial da língua escrita por crianças em processo de escolarização" (SOARES, 2004, p. 31, grifo nosso).

Street (2014), escrevendo sobre Letramentos Sociais, tratando do modelo "ideológico" do Letramento, que considera as práticas sociais específicas de leitura e escrita - em contraposição ao modelo "autônomo" de Letramento, que o associa a "progresso" e "civilização" -, ressalta "a importância do processo de socialização na construção do significado do letramento para os participantes", levando "em conta as percepções locais", a fim de evitar uma visão “forasteira” do letramento (STREET, 2014, p. 44, 47).

Compartilhamos desse posicionamento, ao trabalhar com países de língua portuguesa, por uma perspectiva horizontal de cooperação, construindo cada um sua identidade cultural própria, com as concepções do seu convívio, da socialização e da interação social do cotidiano. Sabemos que, em experiências anteriores, Paulo Freire e a equipe do Instituto de Ação Cultural/IDAC - Guiné- 
Bissau (FREIRE et al., 1982) já pensavam e agiam assim, pois tinham clareza do papel da assessoria: os assessores não deviam "fazer por", não deveriam substituir a própria população nem seus dirigentes. A ajuda verdadeira, dizia ele, "é aquela em que os que nela se envolvem se engajam mutuamente, crescendo juntos no esforço comum de conhecer a realidade que buscam transformar" (FREIRE, 1977, p. 16).

\section{CONSIDERACְ̃̃ES FINAIS}

Os cinco países africanos de língua portuguesa encontramse em situação semelhante, de multilinguismo, utilizando como oficial a língua da colonização: Angola, Cabo Verde, Guiné-Bissau, Moçambique e São Tomé e Príncipe. No caso moçambicano, por exemplo, em consequência de grandes batalhas sociolinguísticas, segundo o $104^{\circ}$ Boletim do Instituto Internacional da Língua Portuguesa/IILP, o Ministério da Educação e Desenvolvimento Humano de Moçambique anunciou, em 18 de março de 2015, que o ensino primário vai usar as 16 línguas nacionais, chamadas de línguas nativas, apontando para o ensino bilíngue.

Nesse sentido, Diallo, reportando-se a essa questão africana, destaca a importância de uma política linguística como um imperativo pedagógico, levando-se em conta a realidade sociocultural dos alunos:

Se é verdade que qualquer desenvolvimento procede de uma visão, África deve então dar-se conta de que os seus cidadãos comem, bebem, dormem e sonham através da suas línguas, pelo que o seu desenvolvimento deve ser construído na base do instrumento que exprime da melhor maneira os seus sonhos, interesses, suas necessidades e aspirações. (DIALLO, 2007, p. 26)

No seu papel de etnógrafo e historiador, Carreira constata: “O problema da adopção de uma língua africana a nível de língua oficial (é o caso de Serra Leoa, de Cabo Verde, da Guiné, etc.) aparenta-se meritório e marca bem o grau de evolução mental de certos sectores cultos dos jovens países" (Carta a Christopher Fyfe, de 19/11/1982, Cf. LOPES FILHO, 2015, p. 102).

Para o historiador africano Joseph Ki-Zerbo (2009, p. 72), "pensar o Estado, a partir da natureza plurinacional das sociedades, seria necessário, na minha opinião, regressar à alfabetização e à escolarização nas línguas maternas africanas". Para o autor, alfabetizar nas línguas maternas seria necessário à sociedade africana como um todo (CÁ, 2015, p. 90). 
Nesse sentido, este texto, que tratou de duas pesquisas realizadas, no âmbito do terceiro eixo da Pesquisa em Rede - tensão entre língua oficial/línguas maternas - tende a apontar a necessidade de pesquisadores/educadores, bem como administradores e representantes políticos, repensarem os contextos multilíngues africanos de língua portuguesa nos moldes do que pensa Veiga (2004, p. 12), a partir do seu país, não somente quando afirma que "a língua primeira constitui a melhor referência na aprendizagem de uma segunda língua", mas também, e sobretudo, em relação à Construção do Bilinguismo Funcional:

Ao português que já é língua oficial e de situações formais de comunicação, tornase necessário alargar o seu ensino e conferir-lhe o estatuto de língua do quotidiano informal, em paridade com a Lcv [Língua Caboverdiana]. Quanto à Lcv que já é língua do quotidiano informal, há que se reconhecer-lhe o estatuto oficial em paridade com a Lp, reforçar o seu uso formal e implementar o seu ensino, do primário ao universitário [...] Tal política linguística é uma exigência da nossa história, da nossa cultura, da nossa identidade (VEIGA, 2004, p. 129, grifo nosso).

Dessa forma, será possível a cada país, repensando a especificidade dos seus aspectos histórico-culturais, considerar tanto o valor histórico/simbólico da Língua da Colonização, quanto o valor cognitivo/cultural das Línguas Locais.

\section{REFERÊNCIAS}

AMÂNCIO, I. M. C.; GOMES, N. L.; JORGE, M. L. S. Literaturas africanas e afrobrasileira na prática pedagógica. Belo Horizonte: Autêntica, 2008.

AUGEL, M. P. O crioulo guineense e a oratura. Scripta, Belo Horizonte, v. 10, n. 19, p. 69-91, 2006.

BUNZEN, C. S; ROJO, R. H. R. Livro didático de Língua Portuguesa como gênero do discurso: autoria e estilo. In: COSTA VAL, M. da G.; MARCUSCHI, B. (Org.). Livros didáticos de Língua Portuguesa: letramento e cidadania. Belo Horizonte: CEALE/ Autêntica, 2005. p. 73-118.

CÁ, V. J. B. Língua e ensino em contexto de diversidade linguística e cultural: o caso de Guiné-Bissau. 2015. 175 f. Dissertação (Mestrado em Educação) - FAE - UFMG, Belo Horizonte. 2015. Disponível em: <http://www.bibliotecadigital.ufmg.br/dspace/ handle/1843/BUBD-9XCK5W>. Acesso em: 6 abr. 2015.

CALVET, L-J. As políticas linguísticas. São Paulo: Parábola Editora, 2007.

CARDOSO, A. J. As interferências linguísticas do caboverdiano no processo de aprendizagem do português. 2005.335 f. Dissertação (Mestrado em Relações Interculturais) - Universidade Aberta, Lisboa. 2005. Disponível em: < https://repositorioaberto.uab.pt/ bitstream/10400.2/633/1/LC225.pdf>. Acesso em: 6 abr. 2015. 
CARREIRA, A. O Crioulo de Cabo Verde, Surto e Expansão. 2. ed. Lisboa: Autor, 1984. CASTRO, R. V.; RODRIGUES, A.; SILVA, J. L.; SOUSA, M. de L. D. (Ed.). Manuais escolares: Estatuto, funções, história. In: ENCONTRO INTERNACIONAL SOBRE MANUAIS ESCOLARES, 1., Braga. Atas... Braga: Universidade do Minho, 1999.

COSTA VAL, M. da G.; MARCUSCHI, B. Livros didáticos de língua portuguesa: letramento, inclusão e cidadania. Belo Horizonte: Autêntica, 2005.

DIALLO, I. Guiné-Bissau: Que papel e que lugar para as línguas nas políticas nacionais de desenvolvimento e estratégias de integração subregional? Bissau: INEP, 2007.

DIONÍSIO, M. de L. T. A construção escolar de comunidades de leitores: leituras do manual de Português. Coimbra: Almedina, 2000.

DIONÍSIO, M. de L. T. Facetas da literacia: processos da construção do sujeito letrado. Educação em Revista, Belo Horizonte, v. 44, p. 41-67, 2006.

FAIRCLOUGH, N. Discurso e mudança social. Brasília: Universidade de Brasília, 2001.

FORQUIN, J-C. Escola e cultura: as bases sociais e epistemológicas do conhecimento escolar. Tradução de Guacira Lopes Louro. Porto Alegre: Artes Médicas, 1993.

FREIRE, P. Cartas à Guiné-Bissau: registros de uma experiência em processo. Rio de Janeiro: Paz e Terra, 1977.

GADOTTI, M. Segunda Parte. Paulo Freire na África: Encontro da pedagogia freiriana com a práxis política de Amílcar Cabral. In: ROMÃO, J. E. (Org.). Paulo Freire e Amílcar Cabral: a descolonização das mentes. São Paulo: Editora e Livraria Instituto Paulo Freire, 2012. p. 55-107. Disponível em: < http://www.acervo.paulofreire.org:8080/jspui/ bitstream/7891/35 91/1/FPFPTPF12094.pdf>. Acesso em: 11 set. 2015.

GOMES, S. F. Relações entre língua oficial e línguas locais na escola: como as crianças de aldeias de Cabinda/Angola aprendem o português e em português. 2014. $154 \mathrm{f}$. Dissertação (Mestrado em Educação) - FAE - UFMG, Belo Horizonte. 2014. Disponível em: <http://www.bibliotecadigital.ufmg.br/dspace/handle/1843/BUOS-9N5LDM>. Acesso em: 6 abr. 2015.

IDAC (Instituto de Ação Cultural). Guiné-Bissau '79: Learning by living and doing. Geneve: Instituto de Ação Cultural, 1979.

IILP - Instituto Internacional da Língua Portuguesa. Boletim 104. 18 março 2015. Disponível em: <https://iilp.wordpress.com/2015/03/18/ensino-primario-mocambicanosera-ministrado-nas-16-linguas-nativas-a-partir-de-2017/>. Acesso em: 6 abr. 2015.

KI-ZERBO, J. Para quando a África? Entrevista com René Holenstein. Tradução de Carlos Aboim de Brito. Rio de Janeiro: Pallas, 2009. 172 p.

LOPES, J. de S. M. Poesia e etnicização nos livros didáticos de português: um estudo comparativo Moçambique e Brasil Curitiba: Editora CRV, 2014.

LOPES FILHO, J. António Carreira: Etnógrafo e Historiador. Praia: Fundação João Lopes, 2015.

MACIEL, F. Aprender a ler e a escrever em São Tomé e Príncipe: análise de Manuais Escolares. In: CONGRESSO INTERNACIONAL DA AILP, 4., 2014, Macau. Resumos... Universidade de Macau, Macau, China, 2014.

MUNANGA, K.; GOMES, N. L. O Negro no Brasil de Hoje. Global: São Paulo, 2006.

PAULINO, G.; COSSON, R. Letramento literário: para viver a literatura dentro e fora da escola. In: ZILBERMAN, R.; RÖSING, T. (Org.). Escola e leitura: velha crise; novas alternativas. São Paulo: Global, 2009. p. 61-80. 
ROJO, R. H. R. Letramentos múltiplos, escola e inclusão social. São Paulo: Parábola Editorial, 2009.

SANTOS, B. S.; MENESES, P. (Org.). Epistemologias do Sul. São Paulo: Cortez, 2010.

SCANTAMBURLO, L. Dicionário do Guineense: dicionário guineense - português; dicionário guinensi-purtuguis. v. 2. Lisboa: Colibri; Guiné-Bissau: FASPEBI, 2002.

SCANTAMBURLO, L. O Léxico do Crioulo Guineense e as suas Relações com o Português: o Ensino Bilingue Português-Crioulo Guineense. 2013. 358 f. Tese (Doutorado em Linguística) - Universidade Nova de Lisboa, Lisboa. 2013. Disponível em: <http:// www.clunl.edu.pt $/ \mathrm{pt} /$ ?det $=833 \&$ section $=\&$ title $=$ Dissertacoes-de-Doutoramento-20032014\&id=1448\&mid $>$. Acesso em: 11 set. 2015.

SEMEDO, M. O. C. Entre o ser e o amar. Bissau: INEP, 1996.

SEMEDO, M. O. C. S. As Mandjuandadi: Cantigas de Mulher na Guiné-Bissau: da tradição oral à literatura. 2010. 452 f. Tese (Doutorado em Literaturas de Língua Portuguesa - Pontifícia Universidade Católica de Minas Gerais/PUC-MG, Belo Horizonte. 2010. Disponível em: <http://www.biblioteca.pucminas.br/teses/LetrasSemedoMO1.pdf>. Acesso em: 6 abr. 2015.

SENA, L. de. Uma experiência de integração da educação na Guiné-Bissau. Soronda. Revista de Estudos Guineenses, Bissau, n. 19, p. 63-88, 1995.

SILVA, P. V. B. da; ROSEMBERG, F. Brasil: lugares de negros e brancos na mídia. In: VAN DIJK, T. Racismo e discurso na América Latina. São Paulo: Contexto, 2008. p. 73-119.

SOARES, M. Letramento: um tema em três gêneros. Belo Horizonte: Autêntica, 1998.

SOARES, M. Português: uma proposta para o letramento. Livro do Professor. São Paulo: Moderna, 1999.

SOARES, M. Letramento e alfabetização: as muitas facetas. Revista Brasileira de Educação, v. 25, p. 5-17, 2004. Disponível em: <http://dx.doi.org/10.1590/S1413$24782004000100002>$. Acesso em: 11 set. 2015.

STREET, B. Letramentos sociais: abordagens críticas do letramento no desenvolvimento, na etnografia e na educação. São Paulo: Parábola Editora, 2014.

VAN DIJK, T. A. Racismo e discurso na América Latina. São Paulo: Contexto, 2008.

VEIGA, M. A Construção do Bilinguismo. Praia-Cabo Verde: Instituto da Biblioteca Nacional e do Livro, 2004.

\section{NOTAS}

${ }^{1}$ A Lei 10.639/03 foi atualizada pela Lei 11.645/08, evidenciando os estudos sobre os afrobrasileiros e os indígenas.

${ }^{2}$ Sobre os outros países africanos de língua portuguesa, Cabo Verde, Moçambique e São Tomé e Príncipe (aqui não estamos considerando ainda, por falta de dados, Guiné Equatorial, que adotou recentemente a língua portuguesa), ver outros estudos, como, por exemplo: Veiga (2004); Lopes (2014); Maciel (2014).

Submetido: 03/06/2016

Aprovado: 03/08/2016

Contato:

Aracy Alves Martins 
Rua Bom Jesus da Penha, 689, Bloco 39, apto. 203 Bairro Santa Terezinha

Belo Horizonte |MG | Brasil

CEP 31.365-190

Silvestre Filipe Gomes

Universidade Onze de Novembro / UON

Rua Comendador Herinque Serrano

Bairro Marie Nguabi

Cabinda-ANGOLA

CP 380

Virgínia José Baptista Cá

Bairro Militar / Plak 1

Bissau

GUINÉ-BISSAU 